\title{
Stabilization of the brain temperature in mammals of different body size under various ambient temperatures
}

\author{
Eugenia TĘGOWSKA
}

\begin{abstract}
Teqgowska E. 1991. Stabilization of the brain temperature in mammals of different body size under various ambient temperatures. Acta theriol. 36: $179-186$.

Brain temperature $\left(\mathrm{T}_{\mathrm{Br}}\right)$ was measured with accuracy $0.05^{\circ} \mathrm{C}$ in 9 species of mammals weighing from 7 to $3850 \mathrm{~g}$. Experiments were performed at ambient temperatures $\left(\mathrm{T}_{\mathrm{A}}\right)$ ranging from 0 to $35^{\circ} \mathrm{C}$. There was found a negative correlation between body size and the dependence of brain temperature on ambient temperature. However, the pattern of changes of $\mathrm{T}_{\mathrm{Br}}$ and the fact that the increase of $\mathrm{T}_{\mathrm{Br}}$ after noradrenaline injection was higher than the drop of $\mathrm{T}_{\mathrm{Br}}$ after cold exposure of animals, suggested that this dependence did not result from low thermal inertia. Results suggested that changes of $\mathrm{T}_{\mathrm{Br}}$ may be an adaptation to thermal economy, even at the cost of accuracy of homeothermia of the brain.

Department of Animal Physiology, Institute of Biology, N. Copernicus University, Gagarina 9, 87-100 Toruń, Poland

Key words: brain temperature, body size, mammals
\end{abstract}

\section{Introduction}

Mammals maintain their body temperature more or less constant and independent of variation in environmental temperatures. To maintain a stable body temperature, there is one fundamental requirement: the rate of heat loss must equal the rate of heat production. In the cold, the smaller the mammal the more difficult it is to balance heat production against the increasing surface-volume ratio.

In spite of this, small mammals inhabit all regions of Earth. These animals during their life time are mostly exposed to temperatures below thermoneutral zone. In these conditions the heat loss from amimals' bodies tends to increase, and in order to maintain a constant body temperature it must be compensated by heat production.

According to Hart's formula (Hart 1963) heat loss depends on temperature gradient between body and environment, and on insulation of body surface area. Small mammals limit heat loss by insulative and posture changes, social thermoregulation and building of the nest (Hart 1956, Hensel et al. 1973). Hart's formula suggested that also a reduction of difference between body and ambient temperatures limit heat loss. Drop of body temperature may be controlled (reduced set-point of thermostat), or may result from thermal insufficiency. In order to find if small mammals regulate a decrease of the body temperature it must be shown, that drop of body temperature is associated with a reserve of thermogenesis.

The main goal of this study was therefore to examine the level and accuracy of stabilization of brain temperature $\left(\mathrm{T}_{\mathrm{Br}}\right)$ in mammals of different body size at various ambient temperatures $\left(\mathrm{T}_{\mathrm{A}}\right)$. I aimed also to find out if the decrease of body temperature in cold 
environment is connected only with low thermal inertia or also with adaptation to thermal economy.

\section{Methods}

Nine species of mammals: Oryctolagus cuniculus (Linnaeus, 1758) weighing $3850 \mathrm{~g}$, Cavia porcellus (Linnaeus, 1758) - 560g, Mesocricetus auratus (Waterhouse, 1839) - 98g, Microtus arvalis (Pallas, 1779) 34g, Clethrionomys glareolus (Schreber, 1780) - 30g, Apodemus agrarius (Pallas, 1771) - 28g, Apodemus flavicollis (Melchior, 1834) - 20g, wild hous mice Mus musculus Linnaeus, $1758-12 \mathrm{~g}$, and Micromys minutus (Pallas, 1771) $-7 \mathrm{~g}$, were used in experiments.

Rabbits, hamsters and guinea pigs were bred in our laboratory. Wild rodents were trapped in their natural habitats near Brodnica (northeastern Poland). All wild animals were obtained from October to the end of February. They were acclimatized to laboratory conditions for a week and individuals apparently free of clinical disease were used in experiments. All animals were kept in single cages with wood shavings in a temperature controlled cabinet at an ambient temperature of $21^{\circ} \mathrm{C}$ and natural light-dark schedule. They were fed oat flakes and water ad libitum, the rabbits and guinea pigs were also given oats, dried bread and hay. All animals received fresh vegetables twice a week (carrot, red beet, or mangel, potatos and apples, or tomatos). A week before the experiments a $\mathrm{Co}$-Cu thermocouple was implanted in hypothalamic region under general anaesthesia (Ketanest) and was fixed to the skull with dental cement and connected with the socket on animal's head.

The brain temperature in free moving mammals was recorded with accuracy $0.05^{\circ} \mathrm{C}$ on a compensation recorder KV 12 VEB Messgerätwerk Erich Weinert, Germany, using as a preamplifier a digital nanovoltmeter Model 180 Keithley Instruments Incorporation, USA.

During the experiments cables were hung up on a stretched elastic and were led through an oulet in the celing. Behavioral observations were noted as the thermal data were taken. All measurements were made between 8 a.m. and 4 p.m. Five species (Oryctolagus cuniculus, Mesocricetus auratus, Clethrionomys glareolus, Apodemus agrarius and Mus musculus) were used for the noradrenaline test to study thermal efficacy of nonshivering thermogenesis. These experiments were performed in an ambient temperature of $25^{\circ} \mathrm{C}$, which is connected with the smallest oscillations of $\mathrm{T}_{\mathrm{Br}}$.

Significance of differences betweet $\mathrm{T}_{\mathrm{Br}}$ of animals were tested using Student's test for unpaired data. The correlation between body weight and the dependence of brain temperature from ambient temperature was calculated. This was aimed to correlat of three data : $\mathrm{T}_{\mathrm{A}}, \mathrm{T}_{\mathrm{Br}}$ and body mass. First of all the correlation curves $\mathrm{T}_{\mathrm{A}}$ vs $\mathrm{T}_{\mathrm{Br}}$ in each species were calculated. Then the angles between these curves and axis $x$ were measured and tangents of the angles were calculated. Finally the values of the tangents of angles were plotted on $y$ axis and the animal weight on $x$ axis.

\section{Results}

The effect of ambient temperature ( $\left.\mathrm{T}_{\mathrm{A}}\right)$ on the level of stabilization of brain temperature $\left(\mathrm{T}_{\mathrm{Br}}\right)$ depending on body size.

Ambient temperature influenced $\mathrm{T}_{\mathrm{Br}}$ of experimental animals. There are two groups of animals : (1) $\mathrm{T} \mathrm{Br}$ of rabbits and guinea pigs - is not dependent on ambient temperature, (2) $\mathrm{T} \mathrm{Br}$ of remaining species is dependent on ambient temperature, especially of A. flavicollis and $M$. minutus. In majority of studied mammals the drop in the brain temperature was not continuous, but ran through lower and lower level of stabilization. Only in 4 out of 8 species a drop of ambient temperatures from 5 to $0^{\circ} \mathrm{C}$ was connected with decrease of $\mathrm{TBr}$, whereas drop of $\mathrm{T}_{\mathrm{A}}$ from 20 to $15^{\circ} \mathrm{C}$ was connected with a decrease of $\mathrm{T}_{\mathrm{Br}}$ in 7 out 9 animals (Table 1, Fig. 1). 
The biggest drop in $\mathrm{T}_{\mathrm{Br}}$ between 35 and $0^{\circ} \mathrm{C}$ could be seen in A. flavicollis weighing $20 \mathrm{~g}$, but not in house mice weighing $12 \mathrm{~g}$.

There are correlations between the level of stabilization of $\mathrm{T}_{\mathrm{Br}}$ and $\mathrm{T}_{\mathrm{A}}$ in all experimental animals (Table 2), and correlation between body weight and the dependence of the brain temperature from ambient temperature (Fig. 2).

The lability of the brain temperature induced by changes in $T_{A}$ depending on body size

The highest lability appeared in the smallest animals - Mus musculus and Apodemus flavicollis, but the highest stability of $\mathrm{T}_{\mathrm{Br}}$ appeared in the biggest - Oryctolagus cuniculus, but also in Clethrionomys glareolus weighing only $30 \mathrm{~g}$ (Table 1).

Table 1. The correlation coefficients $(r)$ between the level of stabilization of $\mathrm{T}_{\mathrm{Br}}-$ versus $\mathrm{T}_{\mathrm{A}}$ in each of animals. $\mathrm{N}$-number of experiments.

\begin{tabular}{lccc}
\hline Species & $\mathrm{N}$ & $r$ & \multicolumn{1}{c}{$p$} \\
\hline Oryctolagus cuniculus & 8 & 0.801 & $p<0.02$ \\
Cavia porcellus & 8 & 0.945 & $p<0.001$ \\
Mesocricetus auratus & 8 & 0.851 & $p<0.01$ \\
Microtus arvalis & 8 & 0.854 & $p<0.01$ \\
Clethrionomys glareolus & 8 & 0.738 & $p<0.05$ \\
Apodemus agrarius & 8 & 0.735 & $p<0.05$ \\
Apodemus flavicollis & 8 & 0.905 & $p<0.01$ \\
Mus musculus & 8 & 0.841 & $p<0.01$ \\
Micromys minutus & 4 & 0.989 & $p<0.01$
\end{tabular}

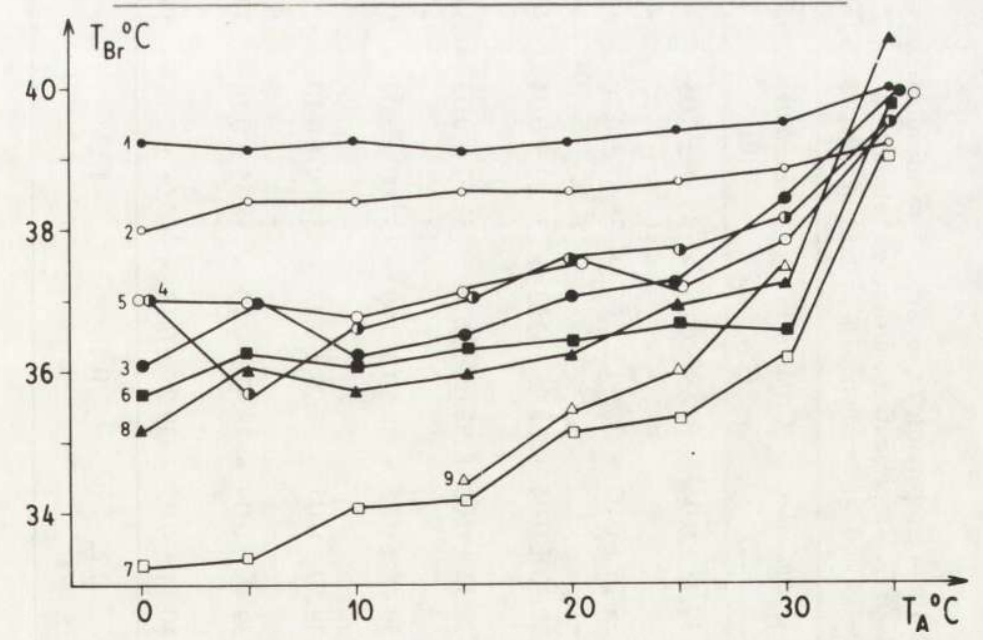

Fig. 1. Brain temperature $\left(\mathrm{T}_{\mathrm{Br}}\right)$ of mammals of different body size in various ambient temperatures $\left(\mathrm{T}_{\mathrm{A}}\right)$. (1) Oryctolaguscuniculus, (2) Cavia porcellus, (3) Mesocricetus auratus, (4) Microtus arvalis, (5) Clethrionomys glareolus, (6) Apodemus agrarius, (7) Apodemus flavicollis, (8) Mus musculus, (9) Micromys minutus. Standard error and number of experiments are given in Table 1. 


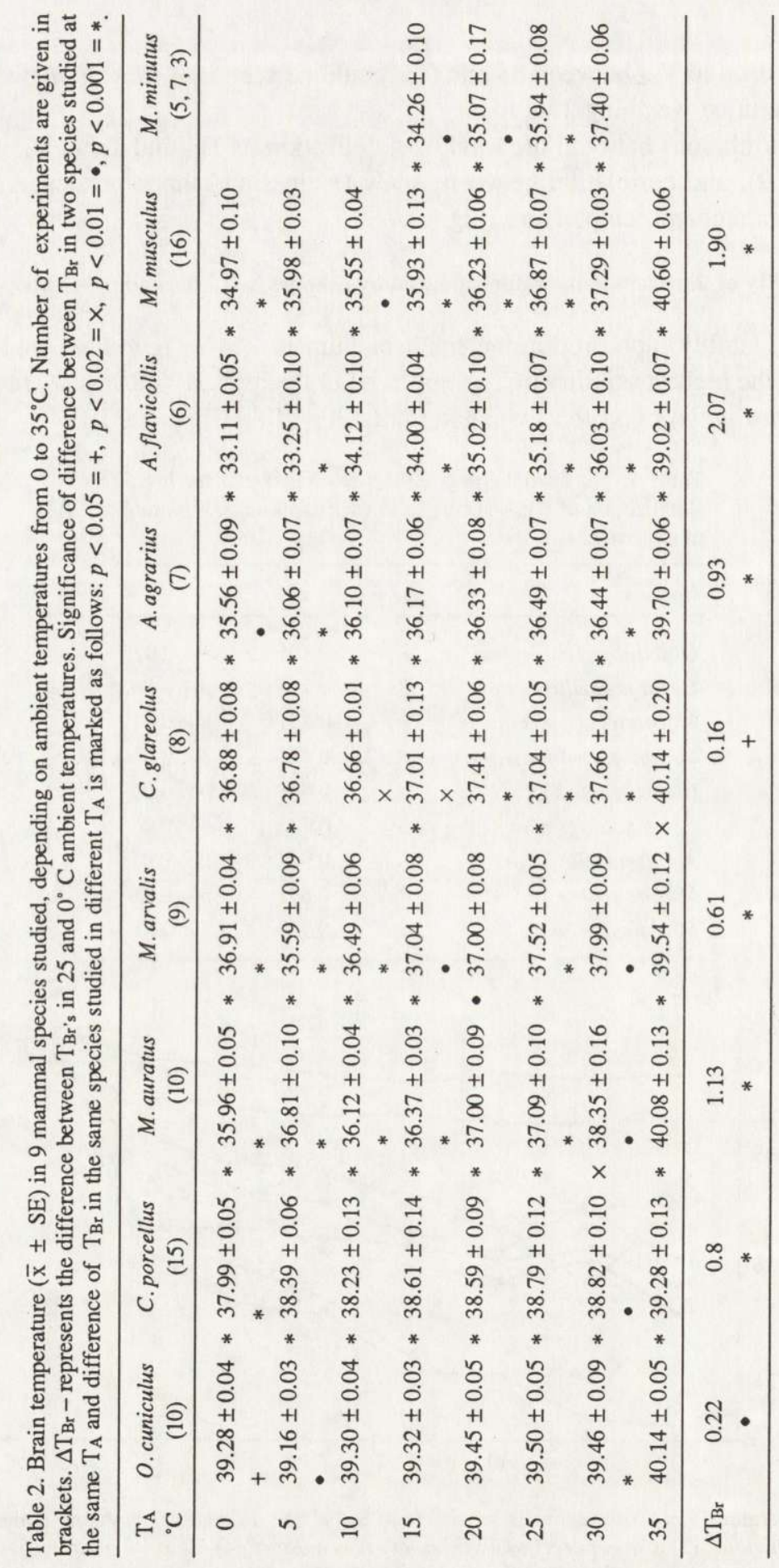




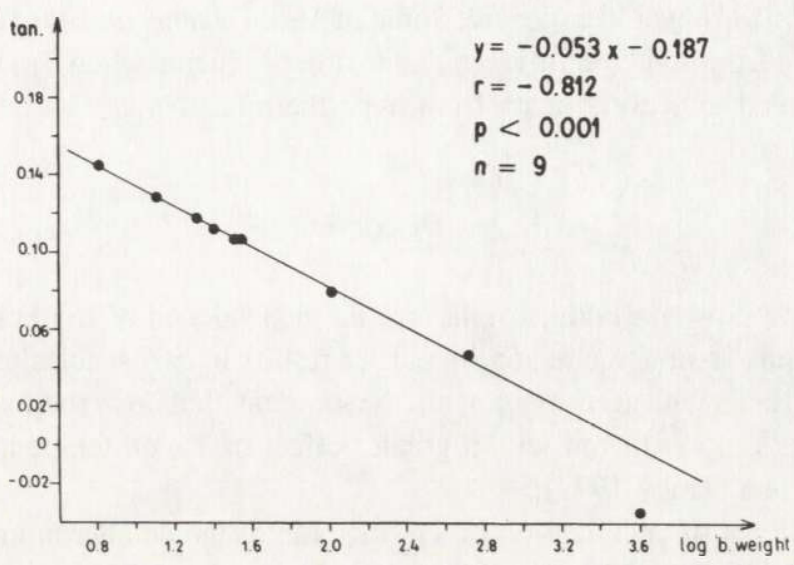

Fig. 2. Correlation between size and the dependence of the brain temperature from ambient temperature $(\tan )(\mathrm{r}=-0.812, p<0.001, \mathrm{n}=9)$. See Methods for details.

Table 3. Changes of the brain temperature $\left(\mathrm{T}_{\mathrm{Br}}\right)$ after inducing nonshivering thermogenesis - i.p. $1.6 \mathrm{mg} / \mathrm{kg}$ noradrenaline (NA) injection. $\mathrm{N}$ - number of experiments. Maximal increase in $\mathrm{T}_{\mathrm{Br}}$ represents the attained (not means).

\begin{tabular}{lcrc}
\hline Species & $\mathrm{N}$ & $\begin{array}{c}\text { Body } \\
\text { mass } \\
\mathrm{g}\end{array}$ & $\begin{array}{c}\text { Maximal } \\
\text { increase in } \\
\mathrm{T}_{\mathrm{Br}}{ }^{\circ} \mathrm{C}\end{array}$ \\
\hline Oryctolagus cuniculus & 4 & 3850 & 0.2 \\
Mesocricetus auratus & 4 & 98 & 7.2 \\
Clethrionomys glareolus & 3 & 30 & 7.4 \\
Apodemus agrarius & 3 & 28 & 6.95 \\
Mus musculus & 4 & 12 & 1.65 \\
\hline
\end{tabular}

The maximum nonshivering thermogenesis and lability of $\mathbf{T}_{\mathrm{Br}}$

As in $\mathrm{T}_{\mathrm{A}} 25^{\circ} \mathrm{C}$ the differences between individual $\mathrm{T}_{\mathrm{Br}}$ and the mean $\mathrm{T}_{\mathrm{Br}}$ are the smallest, it may be suggested that $\mathrm{T}_{\mathrm{A}} 25^{\circ} \mathrm{C}$ is the temperature of the simplest thermal equilibrium. As $\mathrm{T}_{\mathrm{A}}$ is the temperature nearest to the thermoneutral zone not only in small, but also in larger mammals like rabbit, at that $T_{A}$ the experimental animals received i.p. $16 \mathrm{mg} / \mathrm{kg}$ noradrenaline. This stimulation of nonshivering thermogenesis caused a rise in $\mathrm{TBr}$ (Table 3).

The rise in $\mathrm{T}_{\mathrm{Br}}$ was connected with abrupt thermolytic reactions. The animals stretched on the floor, often changing place and spreading saliva onto their body surface. In spite of these 
thremolityc mechanism the increase in $\mathrm{T}_{\mathrm{Br}}$ after noradrenaline (NA) injection was higher than the decrease in $\mathrm{T}_{\mathrm{Br}}$ during cold exposure. Some of Mesocricetus auratus (2) and Clethrionomys glareolus (2) died from hyperthermia. In the next experiments when $\mathrm{T}_{\mathrm{Br}}$ was close to $42^{\circ}$, the animals were cooled to prevent death from hyperthermia.

\section{Discussion}

The correlation between body weight and the dependence of the brain temperature from ambient temperature is in agreement with earlier results in two species of animals (Tęgowska et al. 1974). It is also in agreement with the opinion that low thermal efficacy and high surface-to-volume ratio is linked with a greater effect of $\mathrm{T}_{\mathrm{A}}$ on temperature of a small body than of a bigger one (Tracy 1977).

However the level of stabilization of $\mathrm{T}_{\mathrm{Br}}$ in some of the smaller animals exposed to cold, e.g. C. glareolus (30g), and $M$. arvalis (34g) is higher than of bigger one, e.g. M. auratus; similarly it is in $20 \mathrm{~g}$ A. flavicollis and $12 \mathrm{~g}$ M. musuclus.

The decrease of $\mathrm{T}_{\mathrm{Br}}$ in cold environment is due not only to low efficacy of thermoregulation because: (1) small cold stress (a decrease of $\mathrm{T}_{\mathrm{A}}$ from 20 to $15^{\circ} \mathrm{C}$ ) caused often a decrease of $\mathrm{T}_{\mathrm{Br}}$ than bigger cold stress (a decrease of $\mathrm{T}_{\mathrm{A}}$ from 5 to $0^{\circ} \mathrm{C}$ ), (2) decrease of $\mathrm{T}_{\mathrm{A}}$ from 10 to $5^{\circ} \mathrm{C}$ or decrease of $\mathrm{T}_{\mathrm{A}}$ from 5 to $0^{\circ} \mathrm{C}$ is connected with the increase, but not decrease of $\mathrm{T}_{\mathrm{Br}}$, e. g. in $M$. auratus and $M$. arvalis respectively. The same pattern of changes in body temperature may be found in another mammals, e.g. in Heterohyrax (Bartholomew and Ratine 1971). This pattern of chnges of $\mathrm{T}_{\mathrm{Br}}$ is not connected with thermal inertia resulted from the differences in body mass because two animals with the same size during cold exposure droped their body temperature (Otomys unsulcatus), or increased (Paratomys brantsii) body temperature (Du Plesius and Erasmus 1989).

The range of differences between of $\mathrm{TBr}$ in animals exposed to $25^{\circ} \mathrm{C}$ and $0^{\circ} \mathrm{C}$ is not connected with body size (Table 1). As we can see, this difference was the smallest in the biggest mammals, i.e. rabbits, but it was also in small $30 \mathrm{~g}$ C. glareolus. Similar departure: $\mathrm{T}_{\mathrm{Br}}$ of $34 \mathrm{~g} \mathrm{M}$. arvalis, and $30 \mathrm{~g} \mathrm{C}$. glareolus had $\mathrm{T}_{\mathrm{Br}}$ more stable than C. porcellus.

The attempt of the answer to the question if the dependence of $\mathrm{TBr}_{\mathrm{Br}}$ on $\mathrm{T}_{\mathrm{A}}$ is connected only with lack of thermogenic efficacy is afforded by data in Table 3. In spite of intense thermolytic rections, the increase of $\mathrm{T} B r$ caused by NA injection was always higher than the decrease of $\mathrm{T}_{\mathrm{Br}}$ after cold exposure. In C. glareolus or example, the increase of $\mathrm{T}_{\mathrm{Br}}$ after NA was about $7.4^{\circ} \mathrm{C}$ when a decrease of $\mathrm{T}_{\mathrm{Br}}$ connected with the changes of $\mathrm{T}_{\mathrm{A}}$ from 25 to $0^{\circ} \mathrm{C}$ was only $0.16^{\circ} \mathrm{C}$.

The lack of correlation between efficacy of nonshiverng thermogenesis and body size in these expriments is not in agreement with Hart's (1963) results, but the magnitude of thermogenesis caused by NA is inversely related to the acclimation temperature it is in agreement with opinion by Janský et al. (1967).

Hart's animals were kept at constant low temperature for a period of 3 weeks. The animals in this experiment were examined without any acclimation to uniform temperature. These animals showed therefore thermogenic efficacy adapted to their own current life conditions 
and differed considerable form species to species. Any comparisons of body size-thermal efficacy were thus impossible.

Small mammals encounter severe problems of temperature regulation during cold stress. The mechanism reducing heat loss from body by improving insulation becomes functional only in species of greater size (fox or larger - Hart 1956), because in small mammals the relative heat loss is so great that the fur cannot protect them sufficiently. Mammals have an additional thermoregulatory mechanism, an increase of heat production, however, additional heat production results in higher demands for energy restitution in the body. As a result, small mammals become independent from $\mathrm{T}_{\mathrm{A}}$, but becomes dependent of food.

As suggested by Hansel et al. (1973), when the difference between the core temperature and external temperature is $10^{\circ} \mathrm{C}$, animals weighing $4 \mathrm{~g}$ have to maintain heat production as big as $138.6 \mathrm{~kJ} / \mathrm{h} \mathrm{kg}$ which means that during $1 \mathrm{~h}$ they utilize $0.0138 \mathrm{~g}$ of fat $(=0.35 \%$ body weight). If the difference between the core temperature and external temperature was diminished even only by $1^{\circ} \mathrm{C}$, according to Hart's formula - animals saved about $10 \%$ of dissipated heat. However, drop of body temperature may originate from inertia connected with small thermal efficacy (despite of maximal metabolic rate), or this drop may be regulated. This regulated decrease of body temperature not connected with maximal metabolic rate may save a considerable quantity of energy. It cannot be excluded that such economy of energy may be the reason why small mammals well tollerate great deviations from normothermic body temperature, e.g. in my experiments M. musculus $1.9^{\circ} \mathrm{C}$, and A. flavicollis $2.08^{\circ} \mathrm{C}$. This view is supported by data Busija and Leffer (1987), who found that reduction of body temperature to $34-35^{\circ} \mathrm{C}$ decreased cerebral metabolic rate $40-50 \%$.

It may be assumed that during cold exposure the drop in body temperature in small mammals is connected not only with high surface-to-volume ratio, but also may be inter-preted as thermoregulation at a lower level. The possibility of temporary resignation from exact homeothermy, even of the brain, may be an adaptation to survive cold exposure with maximal energy economy.

Acknowledgements: This work was supported by grant RP II-12 coordinated by prof. J. Surowiak, Jagiellonian University, Kraków, Poland.

\section{References}

Bartholomew G. A. and Rainy M. 1971. Regulation of body temperature in the rock hyrax Heteroxyrax brucei. J. Mammal. 52: $81-95$.

Busija D. W. and Leffler C. W. 1987. Hypothermia reduces cerebral metabolic rate and cerebral blood flow in newborn pigs. Am. J. Physiol. 235: H 869 - H 873.

Du Plessis A., Erasmus T. and Kerley G. I. H. 1989. Thermoregulatory patterns of two sympatric rodents: Otomys uniculatus and Parotomys brantsii. Comp. Biochem Physiol. 94A: 215 - 220.

Hart J. S. 1956. Seasonal changes in insulation of the fur. Can J. Zool. 34: $53-57$.

Hart J. S. 1963. Physiological responses to cold in nonshivering homeotherms. [In: Temperature: its measurements and control in science and industry. J. D. Hardy, ed.]. Reinhold Publ. Co., New York: 373 - 406.

Hensel H., Brück K. and Raths P. 1973. Homeothermic organisms. IV. Production of body heat. [In : Temperature and life. H. Precht, J. Christophersen, H. Hemsel and W. Larcher, eds]. Springer-Verlag Berlin, Heidelberg, New York: $532-563$. 
Janský L., Bartunkowa R. and Zeisberger R. 1967. Acclimation of the white rat to cold; noradrenaline thermogenesis. Physiol. Bohemoslov. 16: 366 - 372.

Tęgowska E., Narębski J., Kądziela W. and Caputa M. 1974. Zakres zmian temperatury mózgu w obciążeniu termicznym, w zależności od wielkości zwierzęcia. Postępy Astronautyki 17 (2/3): 49 - 57.

Tracy C.R. 1977. Minimum size of mammalian homeotherms: role of the thermal environment. Science 198: $1034-1035$.

Received 6 November 1990, accepted 15 July 1991. 